\title{
THE INFLUENCE OF ACCOUNTING SYSTEM REGARDING ACCOUNTING AND TAXATION OF ENTITIES
}

\author{
Dorel Mates PhD \\ West University of Timisoara \\ Puscas Adriana PhD \\ „Vasile Goldis” Western University of Arad \\ Antonela Ursachi PhD Student \\ Stefan cel Mare University ofSuceava \\ E-mail: antonelaursache@gmail.com

\section{Eduard Ajtay, PhD Student} \\ West University of Timisoara
}

(Received November 2015; Accepted January 2016)

\begin{abstract}
Accounting and taxation in Romania at the beginning of the third millennium are in continuous development, as a result of globalization of the world economy and of connecting the accounting and tax system to the international and European one.

The confluence of the two representative cultures - Anglo-Saxon and Latin-European - has left a strong mark on the Romanian accounting and taxation.

The International Financial Reporting Standards (IFRS) and the European Directives set the line to follow for both the Romanian accounting and the Romanian taxation. We get to ask whether Romania has still got its own strategies of economic, social and cultural development or we are part of a system of strategies where accounting is also included?

Key words: accounting system, tax system, tax planning, harmonisation, convergence, globalisation
\end{abstract}

\section{J.E.L. CODES: M40, M41}

\section{Introduction}

The beginning of the third millennium represented for the Romanian accounting a comprehensive process of adapting to new requirements imposed by the European and international economic and financial globalization worldwide. Thus, accounting has become an articulated system of principles, policies, methods and treatments through which economic and financial information is processed to be useful both for internal and external users. Historical and cultural traditions and not at last usages generated several accounting systems of which the most relevant ones at the international level are: the continental (Latin-European) system and the Anglo-Saxon system. 
Mates D., Puscas A., Ursachi A., Ajtay E. (2016)

The influence of accounting system regarding accounting and taxation of entities

The continental accounting system corresponds to the Latin European culture being promoted by countries such as France, Germany, Italy, Romania etc. It is based on the European directives in this field (currently the Directive 2013/34 / EU of the European Parliament and of the Council on the annual financial statements, the consolidated financial statements and the reports related to certain types of companies) without having its own conceptual framework, but oriented on defending the interests of the state. This system is based on the General Accounting Plan and the accounting information is strongly influenced by the legal form of events and transactions and the true image is obtained by compliance, regularity and fairness.

Under this system taxation is presented by specific regulations that require certain behaviour from the entities as a result of the involvement of economic, political and government factors.

The Anglo-Saxon accounting system is typical for countries like United Kingdom, USA, Netherlands, being developed on the cult of liberalism, traditions and usages that are based on a consistent conceptual framework, structured on not-legally influenced goals, and true image and prevalence of the economic system upon the legal one are the main principles in recognizing and measuring structures in the financial and reporting statements of entities.

From a comparative analysis, the two systems have in common the true image, but interpreted differently, which makes the priority objectives to be different:

\begin{tabular}{|l|l|l|}
\hline & \multicolumn{1}{|c|}{ Influential elements } & \multicolumn{1}{c|}{ Purpose } \\
\hline Continental system & $\begin{array}{l}\text {-legal } \\
\text {-tax }\end{array}$ & $\begin{array}{l}\text { Determination of the taxation calculation } \\
\text { bases as revenues of the state budget }\end{array}$ \\
\hline Anglo-Saxon system & -economic found & Information of investors as equity holders \\
\hline
\end{tabular}

Concluding, through the comparative analysis presented, we could say that in the Anglo-Saxon system, accounting is disconnected from taxation, in opposition to the continental accounting system where there is a close relationship between accounting and taxation.

From the international perspective significant advances have made in recent years in harmonizing the two systems, the binder being the International Financial Reporting Standards (IFRS).

\section{Conceptual delimitations related to compliance, accounting harmonization and convergence}

Reforming the accounting system at the beginning of the $19^{\text {th }}$ century was marked by processes such as compliance, harmonization and convergence.

Accounting compliance aims at aligning national accounting rules to the integration instruments, representative at the regional level, with economic, cultural 
Mates D., Puscas A., Ursachi A., Ajtay E. (2016)

The influence of accounting system regarding accounting and taxation of entities

and social influences imposing continuous transformations marked by convergences and divergences as a consequence of national regulations (Mates, Hlaciuc, Ursachi, Maciuca, 2015).

In Romania, compliance means adapting national accounting regulations to the specific European directives: Directive IV, V, VII, VIII until 2014, and respectively Directive 34 since 01.01.2015.

Compliance aims issues such as: applicability area and reporting currency, form and content of individual and consolidated financial statements, general chart of accounts, structure of annual financial statements and operation of the accounts.

Accounting harmonization refers to the articulation and improvement of national accounting systems so that the information in the financial and reporting statements to be comparable.

By harmonization it is intended on the one hand to meet the information needs of multinational companies and on the other hand the validation of accounting information within the national accounting system which generates a similar and internationally comparable financial indicator system (Mates, 2003).

Accounting harmonization in our country at the beginning of the $3^{\text {rd }}$ millennium is based on the one hand on the compliance with the European directives in the field and on the other hand on the implementation of International Financial Reporting Standards (IAS / IFRS), especially by large entities listed on the stock market. Harmonization and compliance are now well established concepts in the language of professional accountants, of professionals in the field and increasingly in the business world (Mates, Hlaciuc, Ursachi, Maciuca, 2015).

Accounting convergence involves essentially the entire business focus to the purpose of the accounting activity, namely the elaboration and presentation of general financial statements according to unitary models of interest for all users.

In this respect, it is envisaged the concentration of all actions related to the processing of economic information so that the financial statements as main financial reporting structures to fairly reflect the financial position, the financial performance, the cash flows and changes in equity of the entities at the end of the reporting period.

\section{Reviews on the Romanian accounting and tax regulation system}

Romanian accounting at the beginning of the $3^{\text {rd }}$ millennium is based on a set of practical principles and specific treatments according to the European Directives and harmonized in accordance with the International Financial Reporting Standards (IAS / IFRS).

The basic regulations in the field is the Accounting Law no.82/1991, as subsequently amended and supplemented which was sustained by orders and rules issued by the Ministry of Public Finance, such as: OMFP 403/1999; OMPF 94/2001; OMPF 306/2002; OMPF 1752/2009; OMPF 2374/2007; OMPF 

the uniform application of accounting principles, of the rules for valuation and presentation of individual and consolidated financial statements. As of 01.01.2015, the main accounting regulation based on the Directive 2013/34/EU is the Order of the Minister of Public Finance no. 1802 on 29.12.2014 on the individual financial statements and the consolidated financial statements. In the taxation field, the basic regulation is set by the Law 571/2003 and starting on 01.01 .2016 by the Law 227/2015 on the Fiscal Code.

According to the applicable regulations, accounting is considered the activity specialized in measuring, assessing, knowing, managing, and controlling assets, liabilities, equity and financial results. This is influenced by the taxation mechanism that drives the tax planning of entities. One of the major purposes of tax planning is the efficiency, which essentially involves minimizing the tax cost by searching for solutions leading to treasury and management cost reduction.

Judged according to its relationship with taxation, the management of the company is represented by accounting that reflects the management transparency with respect to taxation regulations. Thus, the effectiveness, circumscribed to the tax planning area becomes an instrument of inciting the activity characterized by a dynamic behaviour of the entity in relation to taxation parameters dominated by the efficiency criterion (Mates, 2009).

The analysis of the accounting-taxation relation at the level of the management of the entity requires considering, on the one hand, the fiscal risk incurred by entities in the application of tax laws, but also a certain ability of the taxable subjects when transposing the tax law into practice.

Under these conditions, it is necessary to ensure a balance between the tax authorities' actions aimed at attracting budgetary resources through excessive taxation and the desire of entities to limit taxation, including by the ingenuity and skills of professional accountants (experts, auditors, appraisers, consultants).

Studies in the field have shown that this balance consists in harmonizing the accounting and taxation rules and principles, but also the accounting and taxation interest of stakeholders: the state and the economic entities. This way the reasonable limits of taxation would be ensured, facilitating for the state a safe and reasonable level of budgetary resources, and for entities, the encouragement of investments and consumption, which would lead to economic growth.

\section{Tax system and tax planning of economic entities}

In general, the tax system is defined as a set of principles, requirements and rules by which the State sizes, sets, levies and collects taxes, duties and other similar liabilities.

Thus, the tax system involves a complex mechanism formed by the tax legislation, the tax rules, namely the tools, techniques and procedures by which the state tax 
Mates D., Puscas A., Ursachi A., Ajtay E. (2016)

The influence of accounting system regarding accounting and taxation of entities

policy is realised. This translates into practice through technical elements such as: taxation, taxable object, subject of the tax, payment deadline, tax incentives and penalties arising from failure to comply with tax laws.

Besides the established tax principles, namely neutrality of fiscal measures, certainty of taxation, appropriateness of taxation or taxation fairness and taxation efficiency, the new tax regulations promote a new fiscal principle, namely the taxation predictability. This principle is supposed to ensure the stability of taxes, duties and mandatory contributions for a period of at least one year, which may not be subject to changes in terms of increase or introduction of new taxes, duties and other mandatory contributions.

At the level of economic entities, the fiscal mechanism and the technical taxation elements are found within tax planning whose role is to properly manage taxes, duties and other fiscal obligations. The taxation predictability would grant stability both within the tax system and at the level of the tax planning of economic entities. The quality of actions and decisions taken within tax planning can be appreciated by the measures ordered by the tax authority during tax audits and also by the treasury status.

The main objectives of tax planning concern:

- The integration of tax planning in the overall management of the entity;

- The proper management of tax regulations;

- The minimization of costs and tax risk;

- The acceptance of accounting errors as a result of omissions, misrepresentations, or as a result of entrepreneurial ability in interpreting tax legislation;

- The tax deferral up to the deadline prescribed by tax legislation.

\section{Conclusions}

Accounting and taxation mainly aim at tracking the results of an economic entity at a given time. Accounting regulation and tax planning are crucial in ensuring the balance between the accounting system and tax system of economic entities. The main objective of accounting is related to the true and fair image of the financial position and performance of companies. But this aspect is influenced by the connection between accounting and taxation, and implicitly by the similarities or differences between the accounting system and the tax system. The International Financial Reporting Standards are a first step in diluting the intensity of the relationship between accounting and taxation and in using of a common language in presenting financial information.

\section{Bibliography}

1. Istrate C., Fiscalitatea si contabilitatea in cadrul firmei, Ed. Polirom, Iasi, 2002

2. Mates D., Normalizarea contabilitatii si fiscalitatea intreprinderii, Ed. Mirton, Timisoara, 2003 


\section{JOURNAL OF LEGAL STUDIES}

"Vasile Goldiș" Western University of Arad

Mates D., Puscas A., Ursachi A., Ajtay E. (2016)

The influence of accounting system regarding accounting and taxation of entities

3. Mates si colab, Contabilitatea evenimentelor si tranzactiilor intre standarde, directive si reglementari fiscale, Ed. Mirton, Timisoara, 2009

4. Mates D., Hlaciuc E., Ursachi A., Maciuca G., Accounting convergences and divergences in the context of harmonization and the compliance of national regulations with Directive 2013/34/EU, Annals of the University of Craiova, Economic Sciences Serier Journal, 2015

5. Ristea M., Contabilitatea si fiscalitatea intreprinderii, Ed. Tribuna Economica, Bucuresti, 1995

6. *** The Accounting Law no. $82 / 1991$ as subsequently amended and Supplemented Including the GEO no. 79/2014, Official Journal $902 / 11.12 .2014$

7. *** The Order of the Minister of Public Finance no. 1802/2014 on the individual financial statements and the consolidated financial statements, Official Journal $963 / 2014$

8. *** The Law 227/10.09.2015 on the Fiscal Code 